\title{
The complete genome of Banana streak GF virus Yunnan isolate infecting Cavendish Musa AAA group in China
}

\author{
Wei-li Li ${ }^{1}$, Nai-tong Yu ${ }^{\text {Corresp., } 1,2}$, Jian-hua Wang ${ }^{1}$, Jun-cheng $\mathbf{L i}^{3}$, Zhi-xin Liu ${ }^{\text {Corresp. 1, } 2}$ \\ ${ }^{1}$ Key Laboratory of Biology and Genetic Resources of Tropical Crops, Ministry of Agriculture and Rural Affairs, Institute of Tropical Bioscience and \\ Biotechnology, Chinese Academy of Tropical Agricultural Sciences, Haikou, China \\ 2 Hainan Key Laboratory of Tropical Microbe Resources, Haikou, China \\ ${ }^{3}$ Guangdong Key Laboratory of Tropical and Subtropical Fruit Tree Research, Institute of Fruit Tree Research, Guangdong Academy of Agricultural \\ Sciences, Guangzhou, China
}

Corresponding Authors: Nai-tong Yu, Zhi-xin Liu

Email address: yunaitong@163.com, liuzhixin@itbb.org.cn

Banana streak virus (BSV) belongs to the members of the genus Badnavirus, family Caulimoviridae. At present, BSV contains nine species in the International Committee on Taxonomy of Viruses (ICTV) classification report (2018b release). Previous study indicated that the viral particles of Banana streak virus Acuminata Yunnan (BSV-Acum) were purified from banana (Cavendish Musa AAA group) leaves in Yunnan Province, China, and its complete genome was obtained. To further determine whether this sample infecting with Banana streak GF virus (BSGFV), the polymerase chain reaction (PCR) cloning and complete genome analysis of the BSGFV-YN isolate were carried out in this study. The result showed that Banana streak GF virus Yunnan isolate (BSGFV-YN) infecting Cavendish Musa AAA group was co-infecting this sample. Its genome contains a total of $7325 \mathrm{bp}$ in length with $42 \% \mathrm{GC}$ content. This complete genome sequence was deposited in GenBank under accession number MN296502. Sequence analysis showed that the complete genome of BSGFV-YN was $98.14 \%$ sequence similarity to BSGFV Goldfinger, while it was 49.10 57.09\% to other BSV species. Two phylogenetic trees based on the complete genome and ORFIII polyprotein indicated that BSGFV-YN and other BSV species clustered into a group, while it was the highest homology with BSGFV Goldfinger. Although BSGFVYN and BSGFV Goldfinger were highly homologous, their cultivating bananas are different. The former cultivating banana was from Cavendish Musa AAA group, while the latter cultivating banana was from Goldfinger Musa AAAB group. Comparing with BSGFV Goldfinger, the genome of BSGFV-YN has an extra multiple repetitive sequences in the intergenetic region between ORFIII and ORFI, suggesting that this region might be related to host selection. In summary, a BSGFV-YN distant from BSV-Acum was identified from the same sample, and its complete genome sequence was determined and analyzed. The study extends the polymorphism of BSVs in China and provides scientific clue for the 
evolutionary relationship with host selection of badnaviruses. 


\section{The complete genome of Banana streak GF virus Yunnan}

\section{2 isolate infecting Cavendish Musa AAA group in China}

3 Wei-li Li ${ }^{1}$, Nai-tong $\mathrm{Yu}^{1,2^{*}}$, Jian-hua Wang ${ }^{1}$, Jun-cheng $\mathrm{Li}^{3}$, Zhi-xin Liu ${ }^{12^{*}}$

$4 \quad{ }^{1}$ Key Laboratory of Biology and Genetic Resources of Tropical Crops, Ministry of Agriculture and Rural

5 Affairs, Institute of Tropical Bioscience and Biotechnology, Chinese Academy of Tropical Agricultural

6 Sciences, Haikou 571101, China;

$7 \quad{ }^{2}$ Hainan Key Laboratory of Tropical Microbe Resources, Haikou 571101, China;

$8{ }^{3}$ Guangdong Key Laboratory of Tropical and Subtropical Fruit Tree Research, Institute of Fruit Tree Research,

9 Guangdong Academy of Agricultural Sciences, Guangzhou 510640, China.

10

11 \#Wei-li Li and Nai-tong Yu contributed equally to this research.

12

13 *Corresponding author:

14 Nai-tong Yu, Email: yunaitong@163.com

15 Zhi-xin Liu, Email: liuzhixin@itbb.org.cn

16 Institute of Tropical Bioscience and Biotechnology, Chinese Academy of Tropical Agricultural Sciences

17 Tel: 0898-66890770

Email addresses:

WL: 1124047447@qq.com

NY: yunaitong@163.com

JW:wangjianhua@itbb.org.cn

JL: lijuncheng@gdaas.cn

ZL: liuzhixin@itbb.org.cn 


\section{ABSTRACT}

Banana streak virus (BSV) belongs to the members of the genus Badnavirus, family Caulimoviridae. At present, BSV contains nine species in the International Committee on Taxonomy of Viruses (ICTV) classification report (2018b release). Previous study indicated that the viral particles of Banana streak virus Acuminata Yunnan (BSV-Acum) were purified from banana (Cavendish Musa AAA group) leaves in Yunnan Province, China, and its complete genome was obtained. To further determine whether this sample infecting with Banana streak GF virus (BSGFV), the polymerase chain reaction (PCR) cloning and complete genome analysis of the BSGFV-YN isolate were carried out in this study. The result showed that Banana streak GF virus Yunnan isolate (BSGFV-YN) infecting Cavendish Musa AAA group was co-infecting this sample. Its genome contains a total of 7325 bp in length with $42 \%$ GC content. This complete genome sequence was deposited in GenBank under accession number MN296502. Sequence analysis showed that the complete genome of BSGFV-YN was $98.14 \%$ sequence similarity to BSGFV Goldfinger, while it was $49.10 \sim 57.09 \%$ to other BSV species. Two phylogenetic trees based on the complete genome and ORFIII polyprotein indicated that BSGFV-YN and other BSV species clustered into a group, while it was the highest homology with BSGFV Goldfinger. Although BSGFV-YN and BSGFV Goldfinger were highly homologous, their cultivating bananas are different. The former cultivating banana was from Cavendish Musa AAA group, while the latter cultivating banana was from Goldfinger Musa AAAB group. Comparing with BSGFV Goldfinger, the genome of BSGFV-YN has an extra multiple repetitive sequences in the intergenetic region between ORFIII and $O R F I$, suggesting that this region might be related to host selection. In summary, a BSGFV-YN distant from BSV-Acum was identified from the same sample, and its complete genome sequence was determined and analyzed. The study extends the polymorphism of BSVs in China and provides scientific clue for the evolutionary relationship with host selection of badnaviruses.

Subjects: Virology; Molecular biology; Banana

Keywords: Badnavirus; Banana streak GF virus; Musa spp; Viral genome

\section{INTRODUCTION}

Banana (Musa spp.), a perennial monocotyledonous herb, is the fourth largest food crops and the third largest tropical fruit in the world. Bananas are susceptible to variety of viruses (Gaur et al., 2016), such as Banana streak virus (BSV) (Geering et al., 2011), Banana bunchy top virus (BBTV) (Yu et al., 2012) and Cucumber mosaic virus (CMV) (Khaled et al., 2016). Banana production is threatened by the Banana streak disease (BSD), and its pathogen belongs to the genus Badnavirus, family Caulimoviridae (Alangar et al., 2016). BSV is widely distributed in the main planting areas of banana industry in Southeast Asia and Africa, and it had seriously affected the yield and quality of bananas resulted in huge economic losses (Kumar et al., 2015). Moreover, BSV genome may integrate into the banana genome, and it can be activated to produce infectious virions under certain environmental stress (Gayral et al., 2008; Côte et al., 2010). BSV is a kind of pararetroviruses (EPRVs) that use a virus-encoded reverse transcriptase (RT) to reverse viral RNA (vRNA) into viral DNA, completing the viral DNA replication process (Hohn et al., 2013). BSV possesses an opencircular double-stranded DNA genome of $7-8 \mathrm{~kb}$ in size and its genome is encapsidated inside non-enveloped bacilliform particle (30nm x $150 \mathrm{~nm}$ ) (Selvarajan et al., 2016; Alangar et al., 2016).

The genomic structure of the typical badnavirus consists of three open reading frames (ORFs) in the positive 
strand (Vo et al., 2016). ORF I and ORF II encode proteins of unkown function. ORFIII, the largest ORF, encodes $\mathrm{a} \sim 200 \mathrm{kDa}$ polyprotein which is hydrolyzed by protease to produce a variety of functional proteins related to the viral life cycle, containing movement protein (MP), coat protein (CP), aspartic protease (AP), reverse transcriptase (RT) and ribonuclease H (RNaseH) (Duroy et al., 2014; Alangar et al., 2016). Bioinformatic analysis indicated that the sequence between RT and RNaseH (RT/RNaseH) are the most conserved region in the badnavirus genome. According to the classification of the genus Badnavirus by the International Committee on Taxonomy of Viruses (ICTV), the nucleotide sequence similarity less than $80 \%$ or the amino acid sequence similarity less than $89 \%$ is considered as a new species (Geering et al., 2014). At present, nine BSV species of Banana streak GF virus (BSGFV), Banana streak IM virus (BSIMV), Banana streak MY virus (BSMYV), Banana streak OL virus (BSOLV), Banana streak UA virus (BSUAV), Banana streak UI virus (BSUIV), Banana streak UL virus (BSULV), Banana streak UM virus (BSUMV) and Banana streak VN virus (BSVNV) are identified by ICTV. In addition, three other BSV species of Banana streak CA virus (BSCAV) (James et al., 2011), Banana streak virus-isolate GD (BSV-GD) (He et al., 2009) and Banana streak virus Acuminata Yunnan (BSV-Acum) (Zhang et al., 2011) have not been classified.

The diversities of complete genome sequences of more than nine BSV species indicated that the virus is highly variable and polymorphic (Iskra-caruana et al., 2014). Furthermore, it is difficult to study the invasion mechanism and pathogenesis, owing to the instability of symptoms on the host and the integration of the BSV genome into host genome which can be activated to produce infectious virions under certain environmental stress (Stainton et al., 2015). The genomic characters and sequence diversity of Banana streak virus (BSV) in China are under investigation. Isolation and sequencing of the BSGFV and other new BSVs are greatly abundant the diversity of the badnavirus in China and provides an important data for disease resistance breeding. Based on the characteristics of circle double-stranded DNA molecule of the BSV genome, the complete genome sequence of BSGFV-YN was obtained by segmental PCR amplification, and the genomic structure and evolutionary relationship were further analyzed. The study will extend the polymorphism of BSV in China and provide scientific clue for the evolutionary relationship with host selection of badnaviruses.

\section{MATERILS AND METHODS}

\section{Materials}

Banana leaves showing streak symptoms were collected by permissions of a farmer (Shao-cheng Shen) from Yunnan, China in 2009. The banana belongs to the Cavendish Musa AAA group. Total DNA was extracted and stored at $-80^{\circ} \mathrm{C}$. Previous study showed that the sample was infected with Banana streak virus Acuminata Yunnan (BSV-Acum), and its complete genome was obtained and analyzed in our laboratory (Zhuang et al., 2011). In order to further determine whether other BSV species or strains co-infect in the same plant, the complete genome amplification based on PCR method was conducted on the total DNA.

\section{Cloning and sequencing of viral genome}

According to the complete genome sequence of BSGFV deposited in NCBI (GenBank accession number NC_007002.1), seven specific pairs primers were designed by Primer Premier 5.0 (Table 1). The primers were synthesized by Invitrogen (Guangzhou, China) Trading Co., Ltd. The PCR reaction system $(50 \mu \mathrm{L})$ contained EasyTaq ${ }^{\circledR}$ DNA Polymerase $1 \mu \mathrm{L}$ (Beijing, China), $2.5 \mathrm{mM}$ dNTPs $4 \mu \mathrm{L}, 10 \times$ EasyTaq buffer $5 \mu \mathrm{L}$, $5 \mu \mathrm{M}$ forward and reverse primers $4 \mu \mathrm{L}$, total DNA template $2 \mu \mathrm{L}$, and added $\mathrm{ddH}_{2} \mathrm{O}$ to $50 \mu \mathrm{L}$. PCR reaction 
condition was pre-denaturation at $94^{\circ} \mathrm{C}$ for $3 \mathrm{~min}$; followed by 35 cycles of denaturation at $94^{\circ} \mathrm{C}$ for $30 \mathrm{~s}$, annealing at $55^{\circ} \mathrm{C}$ for $30 \mathrm{~s}$, and extension at $72^{\circ} \mathrm{C}$ for $90 \mathrm{~s}$; and a final extension step at $72^{\circ} \mathrm{C}$ for $10 \mathrm{~min}$. The 6 $\mu \mathrm{L}$ PCR product was analyzed by electrophoresis in $1.5 \%$ agarose gel, and the remaining PCR product was purified by an OMEGA gel recovery kit (Bio-Tek, USA). The purified PCR product of each DNA fragment was cloned into the pMD18-T vector (Takara, China), and then transformed into E. coli DH5a competent cells ( $2^{\text {nd }}$ Lab, Shanghai, China). Three positive clones were randomly selected for Sanger sequencing at Invitrogen (Guangzhou, China).

\section{Complete genome sequence assembly and analysis}

The seven overlapping fragments were edited by ChromasPro software (Technelysium Pty. Ltd., Australia) and were used to assemble into the complete genome of BSGFV-YN by BioEdit software (Hall. 1999). The genome was further analyzed by Blastn and Blastx at NCBI website (http://blast.ncbi.nlm.nih.gov/Blast.cgi), and the possible species or strain of BSV was preliminarily identified. Based on the classification of ICTV (2018b release), 37 badnaviruses were downloaded from GenBank for further comparison and analysis (Table 2). The open reading frames (ORFs) of BSGFV-YN were predicted and analyzed by ORF Finder online website (https://www.ncbi.nlm.nih.gov/orffinder/) and bioinformatic analysis. Subsequently, the sequence similarities of complete genomes, ORF I III and their putative proteins between BSGFV-YN with other 15 badnaviruses were analyzed by Sequence Identity Matrix Program in BioEdit software. The movement protein (MP), coat protein $(\mathrm{CP})$, aspartic protease (AP), reverse transcriptase (RT), ribonuclease $\mathrm{H}(\mathrm{RNaseH})$ and two cysteine-rich domains in BSGFV-YN ORFIII were predicted according to the report by $\mathrm{Li}$ et al (Li et al., 2018), and sequence similarities with other homologous proteins were aligned by the GeneDoc software. The repeated sequences in the intergenic regions between ORFIII and ORF I of BSGFV-YN and BSGFV goldfinger (NC_007002.1) were also analyzed by GeneDoc software.

\section{Phylogenetic analysis}

In order to further determine the homology and evolutionary relationships of BSGFV-YN with other badnaviruses, two phylogenetic trees based on the complete genomes and ORFIII polyproteins of BSGFV-YN and other 37 badnaviruses were constructed by using MEGA6.0 software (Table 2). The evolutionary history was inferred using the Neighbor-Joining method and its distance was computed using the p-distance method (Saitou and Nei. 1987). Meanwhile, to analyze the evolutionary relationship between BSGFV-YN and other BSV species in different banana hosts, a phylogenetic tree was also constructed based on the complete genome sequences.

\section{RESULTS}

\section{Cloning and assembly of BSGFV-YN genome}

To obtain the complete genome sequence of BSGFV-YN, 7 specific pair primers were used for segmental PCR amplification (Fig. 1A). The PCR results showed that each DNA fragment was specifically amplified and the length was consistent with the expected size. Bioinformatic analysis showed that the sequence of each fragment was highly similar to the BSGFV by blastn. The seven overlapping DNA fragments were assembled via head-to-tail method by BioEdit software, and a circular double-stranded DNA of 7325 bp with 42\% GC was finally obtained. The complete genome sequence of BSGFV-YN was deposited in GenBank under 
150

151

152

153

154

155

156

157

158

159

160

161

162

163

164

165

166

167

168

169

170

171

172

173

174

175

176

177

178

179

180

accession number MN296502.

\section{Genomic analysis of BSGFV-YN}

Sequence analysis showed that the characteristic of BSGFV-YN complete genome was similar to the typical badnavirus. In detail, the BSGFV-YN contains three open reading frames (ORFs) on the positive strand of viral genome. The first ORF (ORF I) was found at 484-1011 bp while the second ORF (ORF II) was located at 1008-1346 bp, both of which were predicted to encode proteins with unknown function. However, the third ORF (ORF III) located at 1343-6841 bp encoded a polyprotein with the largest in size (Fig. 1B). Further analysis revealed that the termination codon region of BSGFV-YN ORF I has a 4-base overlap (ATGA) with the start codon region of $O R F$ II; similarly, the termination codon region of ORF II and the start codon region of ORFIII are also overlap of a 4-base, with ATGA as well.

Complete genome sequence analysis showed that BSGFV-YN was $98.14 \%$ sequence similarity with BSGFV Goldfinger, while it was 49.10-57.09\% sequence similarity with other BSV species. The genome size of BSGFV is the smallest among all BSV species. In addition, the sequence similarity of BSGFV-YN with Canna yellow mottle associated virus (CaYMV), Kalanchoe top-spotting virus (KTSV), Pineapple bacilliform CO virus (PBCOV), or Sugarcane bacilliform MO virus (SBMOV) was 53.58\%, 52.92\%, 51.49\% and 49.16\%, respectively. Further, the BSGFV-YN ORFs ( I III) were $99.43 \%, 99.11 \%$ and $98.91 \%$ nt sequence similarities with those of BSGFV Goldfinger, while they shared $99.62 \%, 98.82 \%$ and $99.02 \%$ at the amino acid levels. The sequence similarity between BSGFV-YN ORFs ( I III) and other badnaviruses ORFs ( I III) were even more lower (Supplemtary Table S1).

Badnavirus ORFIII, the largest ORF, encodes a $200 \mathrm{kDa}$ polyprotein, which can be hydrolyzed by protease into several small proteins, such as MP, CP, AP, RT and RNase H. In this study, BSGFV-YN ORFIII polyprotein also contains MP, CP, AP, RT, RNaseH and two cysteine-rich zinc finger-like RNA-binding regions (Fig. 1B and Fig. 2). The domains of BSGFV-YN ORFIII are highly similar or identical to the corresponding domains of BSGFV Goldfinger. Further analysis showed that the RT domain was the most conservative with the similarity of $72.25 \sim 84.29 \%$, while the AP was the most variable, with the similarity of 39.39 66.33\% (Supplemtary Table S2).

The non-coding region of BSGFV-YN genome is $968 \mathrm{bp}$, which contains a specific binding site, the 12 bases (5'-TGG TAT CAG AGC-3'), of tRNA ${ }^{\text {met }}$. This binding site is a common feature among all badnaviruses. The first nucleotide "T" is a highly conserved base required for replication and is set as the starting base of the sequence. The non-coding region also contains a TATA box domain (TATATA), which is located at 7162$7168 \mathrm{bp}$. In addition, the non-coding region has a $63 \mathrm{bp}$ sequence that longer than BSGFV Goldfinger, and two kinds of repeating sequences were found in the $63 \mathrm{bp}$ and adjacent region. A short repetition "Repeat $\mathrm{S}$ " and relative long repetition "Repeat $L$ " have been found (Fig. 3).

\section{Phylogenetic analysis}

In order to analyze the evolutionary relationships between BSGFV-YN and 37 other badnaviruses, a phylogenetic tree based on their complete genomes was firstly constructed. The results showed that these badnaviruses can be divided into two distinct groups, Group I and Group II. BSGFV-YN and other BSV species were classified into the Group II. Furthermore, 11 BSVs can be further divided into two subgroups, BSV- I and BSV-II subgroups. BSGFV-YN was the highest homology with the BSGFV Goldfinger, but it 
191

192

193

194

195

196

197

198

199

200

201

202

203

204

205

206

207

208

209

210

211

212

213

214

215

216

217

218

219

220

was more close to KTSV than other BSV species (Fig. 4). Similar result has been reported in badnaviruses (Rumbou et al., 2018).

To further determine the phylogenetic relationship, another phylogenetic tree was constructed based on ORFIII polyproteins. The results confirmed that these badnaviruses can be divided into Group I and Group II . However, the Aglaonema bacilliform virus (ABV) group was clustered into Group I, which is different from the result of phylogenetic tree based on the complete genome. This phylogenetic tree also showed that BSGFV-YN had the highest homology with BSGFV Goldfinger (Fig. 5).

As shown in Fig. 6, phylogenetic tree was constructed by the eleven complete genomes of BSVs. The results showed that BSGFV-YN and other BSV species formed to two branches. In detail, BSUMV, BSUIV and BSULV formed to one branch, while BSGFV-YN, BSGFV Goldfinger, BSIMV, BSMYV, BSOLV, BSVNV, BSUAV, and BSV-Acum were clustered into another branch. The BSGFV-YN was the highest homology with BSGFV Goldfinger, which is consistent with results as Fig. 4 and Fig. 5A. It is interesting that BSGFV Goldfinger has been reported to infect Goldfinger (Musa AAAB), but the BSGFV-YN was cloned from another banana line (Musa AAA), indicating the BSGFV can infect different banana varieties.

\section{DISCUSSION}

Currently, fifty-seven members are recognized in the genus Badnavirus of the family Caulimoviridae, including 9 species of BSV, suggesting the high diversity and polymorphism of BSV species. The badnaviruses, one of the important plant viral pathogens, endanger global agriculture. They are widely infecting the economic crops, such as bananas, sugarcane, citrus, cocoa, taro, black pepper, yam and other tropical and subtropical crops resulting in severe diseases (Lee et al., 2015 Alangar et al., 2016). The badnaviruses have been concerned by people recently because some of badnaviruses have been causing significant agricultural economy loss. Among them, BSV is widely distributed in the main planting areas of banana industry (Jaufeerally-Fakim et al., 2006), and its genome can be integrated into the banana host genome which can be activated to produce infectious virions under certain environmental stress (Umber et al., 2016; Chabannes t al., 2013). Based on this situation, the potential endanger by BSV is immeasurable. Therefore, it is very necessary to recognize the genomic structure and polymorphism of BSV, protein function, virus evolution, geographical distribution, host range and pathogenic mechanism by reporting the new BSV species (or strains) on different banana lines.

In this study, the complete genome of the BSGFV-YN (GenBank accession MN296502) was obtained by seven segmental PCR cloning strategies. Previous study has been showed that the sample was infected with Banana streak virus Acuminata Yunnan (BSV-Acum), and its complete genome was obtained from the purified viral particle (Zhuang et al., 2011). Similarly, the BSGFV-YN can be amplified from the viral particle and its genome is episomal in the host banana. BSGFV-YN has a typical genomic characteristic of badnavirus and phylogenetic tree analysis indicated that it is highly homologous to the BSGFV Goldfinger. According to the classification of the ICTV, the amino acid sequence similarity of the RT/RNase H less than $89 \%$ can be determined as a new species. In this study, the RT and RNase H of BSGFV-YN were $100 \%$ and $98.45 \%$ similar to the reported BSGFV Goldfinger, indicating that BSGFV-YN and BSGFV Goldfinger belong to the same BSV species. Although they are highly homologous, their hosts are obviously different. The former banana host is Cavendish Musa AAA group while the latter banana host is Goldfinger Musa AAAB group. We found that BSGFV-YN had an extra specific sequence longer than BSGFV Goldfinger between the intergenic 
232

233

234

235

236

237

238

239

240

241

242

243

244

245

246

247

248

249

250

251

252

253

254

255

256

257

258

259

260

261

262

263

264

265

266

267

268

region of $O R F I I I$ and $O R F I$. Sequence analysis indicated that two kinds of repeated sequence were found. Studies have been shown that BSOLV (NC_003381) was 441 bp longer than BSOLV-IN1/IN2 between the regions of the ORFIII and ORF I, but their host derived from the different banana varieties (Baranwal et al., 2014). The evidence indicates that the repeated sequence of the intergenic region may provide an important clue for the BSGFV infecting different banana hosts, but further experimental evidences are needed.

This study showed that RT was the most conserved domain in the polyprotein, while AP was the lowest conserved. The badnaviruses firstly transcribed genome DNA into the full-length viral RNA (vRNA), and then reverse transcribed to viral DNA by RT to complete viral DNA replication. Therefore, the RT enzyme is conserved in all badnaviruses, which is consistent with its protein function (Li et al., 2018). AP, as a proteolytic enzyme, can hydrolyze the polyprotein into several functional small proteins. Depending on its specific proteolytic sites, we suggested that the conservation of AP is low (Hany et al., 2014; Vo et al., 2016).

\section{CONCLUSIONS}

In summary, BSGFV-YN, a new isolate of the Banana streak GF virus (BSGFV), was cloned from the banana sample of Cavendish Musa AAA group that has been reported infecting with BSV-Acum. Bioinformatics analysis showed that BSGFV-YN is highly homologous to the BSGFV Goldfinger isolated from Musa AAAB group, indicating that BSGFV can infect different banana varieties. BSGFV-YN may be a novel isolate of BSGFV in the new host, which provides an important clue for revealing the polymorphism of BSV genome.

\section{ADDITIONAL INFORMATION AND DECLARATIONS}

\section{Funding}

This study was funded by the Young Elite Scientists Sponsorship Program by CSTC (Project No. CSTCQN201704) and Guangdong Key Laboratory of Tropical and Subtropical Fruit Tree Research, Institute of Fruit Tree Research, Guangdong Academy of Agricultural Sciences (No. 2017B030314113).

\section{Competing interests}

The authors declare that they have no competing interests.

\section{Compliance with ethical standards}

The authors declare that ethical standards have been followed and that no human participants or animals were involved in this research.

\section{Author Contributions}

Nai-tong Yu and Zhi-xin Liu conceived and designed the experiments. Wei-li Li, Jian-hua Wang and Juncheng Li performed the experiments. Wei-li Li, Nai-tong Yu and Zhi-xin Liu analyzed the data, wrote the manuscript. 


\section{REFERENCES}

271

Alangar B, Thomas H, Ramasamy S. 2016. Badnaviruses: the current global scenario. Viruses 8(6):177 DOI 10.3390/v8060177.

Baranwal VK, Sharma SK, Khurana D, Verma R. 2014. Sequence analysis of shorter than genome length episomal Banana streak OL virus like sequences isolated from banana in India. Virus Genes 48(1):120-127 DOI 10.1007/s11262-013-0984-1.

Chabannes M, Baurens FC, Duroy PO, Bocs S, Vernerey MS, Rodier-Goud M. 2013. Three infectious viral species lying in wait in the banana genome. Journal of Virology 87(15):8624-8637 DOI 10.1128/JVI.00899-13.

Côte FX, Galzi S, Folliot M, Lamagnère Y, Teycheney PY, Iskracaruana ML. 2010. Micropropagation by tissue culture triggers differential expression of infectious endogenous Banana streak virus sequences (eBSV) present in the B genome of natural and synthetic interspecific banana plantains. Molecular Plant Pathology 11(1):137-144 DOI 10.1111/J.1364-3703.2009.00583.X.

Duroy PO, Chabannes M, Iskra-Caruana ML, Muller E. 2014. A possible scenario for the evolution of Banana streak virus in banana. Virus Research 186:155-162 DOI 10.1016/j.virusres.2014.01.005.

Gaur RK, Petrov NM, Patil BL, Stoyanova MI. 2016. Viral diseases of banana and their management.

Gayral P, Noa-Carrazana JC, Lescot M, Lheureux F, Lockhart BEL, Matsumoto T. 2008. A single Banana streak virus integration event in the banana genome as the origin of infectious endogenous pararetrovirus. Journal of Virology 82(13):6697-6710 DOI 10.1128/JVI.00212-08.

Geering AD, Maumus F, Copetti D, Choisne N, Zwickl DJ, Zytnicki M, McTaggart AR, Scalabrin S, Vezzulli S, Wing RA, Quesneville H, Teycheney PY. 2014. Endogenous florendoviruses are major components of plant genomes and hallmarks of virus evolution. Nature Communications 5:5269 DOI 10.1038/ncomms6269.

Geering ADW, Parry JN, Thomas JE. 2011. Complete genome sequence of a novel badnavirus, Banana streak IM virus. Archives of Virology 156(4):733-737 DOI 10.1007/s00705-011-0946-7.

Hall TA. 1999. BioEdit: a user-friendly biological sequence alignment editor and analysis program for Windows 95/98/NT. Nucleic Acids Symp Series 41:95-98.

Hany U, Adams IP, Glover R, Bhat AI, Boonham N. 2014. The complete genome sequence of Piper yellow mottle virus (PYMoV). Archives of Virology 159(2):385-388 DOI 10.1007/s00705-013-1824-2.

He YW, Chen X, Ruan XI, Liu FX, Li HP. 2009. Prokaryotic expression of Banana streak virus ORF I gene and preparation of its antiserum. Journal of South China Agricultural University 39(1):100-103 DOI 1001411X(2009)03-0018-04.

Hohn T, Rothnie H. 2013. Plant pararetroviruses: replication and expression. Current Opinion in Virology 3(6):621-628 DOI 10.1016/j.coviro.2013.08.013.

Iskra-Caruana ML, Duroy PO, Chabannes M, Muller E. 2014. The common evolutionary history of badnaviruses and banana. Infection, Genetics and Evolution 21(1):83-89 DOI 10.1016/j.meegid.2013.10.013. 
James AP, Geijskes RJ, Dale JL, Harding RM. 2011. Molecular characterisation of six badnavirus species associated with leaf streak disease of banana in east Africa. Annals of Applied Biology 158(3):346-353 DOI 10.1111/j.1744-7348.2011.00466.x.

Jaufeerally FY, Khorugdharry A,Harper G. 2006. Genetic variants of Banana streak virus in Mauritius. Virus Research 115(1):0-98 DOI 10.1016/j.virusres.2005.06.015.

Khaled AGA, Wardany A, Mahmoud SYM. 2016. Coat protein gene of new isolate of Cucumber mosaic virus infecting banana in Egypt. Journal of Microbiology Biotechnology and Food Sciences 05(2):177-181 DOI 10.15414/jmbfs.2015.5.2.177-181.

Kumar PL, Selvarajan R, Iskra-Caruana ML, Chabannes M, Hanna R. 2015. Biology, etiology, and control of virus diseases of banana and plantain. Advances in Virus Research 91(1):229-269 DOI 10.1016/bs.aivir.2014.10.006.

Lee YJ, Kwak HR, Lee YK, Kim MK, Choi HS, Seo JK. 2015. Complete genome sequence of Yacon necrotic mottle virus, a novel putative member of the genus badnavirus. Archives of Virology 160(4):11391142 DOI 10.1007/s00705-015-2341-2.

Li YC, Shen JG, Zhao GH, Yao Q, Li WM. 2018. A novel endogenous badnavirus exists in Alhagi sparsifolia. Journal of Zhejiang University SCIENCE B 19(4):274-284 DOI 10.1631/jzus.B1700171. Plant viruses: evolution and management 17:289-308 DOI 10.1007/978-981-10-1406-2_17.

Rumbou A, Candresse T, Marais A, Theil S, Langer J, Jalkanen R, Büttner C. 2018. A novel badnavirus discovered from Betula sp. affected by birch leaf-roll disease. PLoS One 13(3): e0193888. DOI 10.1371/journal.pone.0193888.

Saitou N. and Nei M. 1987. The neighbor-joining method: A new method for reconstructing phylogenetic trees. Molecular Biology and Evolution 4(4):406-425 DOI 10.1093/oxfordjournals.molbev.a040454.

Selvarajan R, Balasubramanian V, Gayathrie T. 2016. Highly efficient immunodiagnosis of episomal Banana streak MY virus using polyclonal antibodies raised against recombinant viral-associated protein. Journal of Phytopathology 164(7-8):497-508 DOI 10.1111/jph.12475.

Stainton D, Halafihi Mana'ia, Collings DA, Varsani A. 2015. Genome sequence of Banana streak MY virus from the pacific ocean island of Tonga. Genome Announcements 3(3):e00543-15 DOI 10.1128/genomea.00543-15.

Umber M, Pichaut JP, Farinas B, Laboureau N, Janzac B, Plaisir-Pineau K. 2016. Marker-assisted breeding of Musa balbisiana genitors devoid of infectious endogenous Banana streak virus sequences. Molecular Breeding 36(6):74 DOI 10.1007/s11032-016-0493-8.

Vo JN, Campbell PR, Mahfuzc NN. 2016. Characterization of the Banana streak virus capsid protein and mapping of the immunodominant continuous B-cell epitopes to the surface-exposed N-terminus. Journal of General Virology 97(12):3446-3457 DOI 10.1099/jgv.0.000643.

Yu NT, Zhang YL, Feng TC, Wang JH, Kulye M, Yang WJ, Lin ZS, Xiong Z, Liu ZX. 2012. Cloning and sequence analysis of two Banana bunchy top virus genomes in Hainan. Virus Genes 44(3):488-494 DOI 10.1007/s11262-012-0718-9.

Zhuang J, Wang JH, Zhang XC, Liu ZX. 2011. Molecular characterization of Banana streak virus isolate from Musa Acuminata in China. Virologica Sinica, 26 (6):393-402 DOI 10.1007/s12250-011-3212-y 
Table $\mathbf{1}$ (on next page)

Primers used in this study 
1 Table 1. Primers used in this study.

\begin{tabular}{llll}
\hline Primer & Primer sequence (5' to 3' direction) & Position (nt) & Direction \\
\hline ORFI-F & ATGAACTCCGACCTCAAAGAG & $484-504$ & Forward \\
ORFI-R & TCCAAGAATTGTTTTTCTTAGATGATG & $982-1008$ & Reverse \\
ORFII-F & ATGAACTCAGAGGCATACAAGG & $1008-1029$ & Forward \\
ORFII-R & TTGAATCTCCTTGAGAAGGTCAAAAG & $1318-1343$ & Reverse \\
P1-F & CGGACGTGGTGGACCCAGC & $6844-6862$ & Forward \\
P1-R & CCGAAGGTTGTGAGCTAAGTCAG & $590-612$ & Reverse \\
P2-F & GAACCCTTTTGACCTTCTCAAG & $1313-1334$ & Forward \\
P2-R & TTGTCCCATCTTTTGGGCTTCC & $2751-2772$ & Reverse \\
P3-F & GGGAGCTCTCGGGGTTG & $2699-2715$ & Forward \\
P3-R & GGCAGAACTTCCTTAGTAGTTCG & $4108-4130$ & Reverse \\
P4-F & GCATGACTGGAGAGAACTAGC & $4075-4095$ & Forward \\
P4-R & TACCTCGGAAGCAGTTGTCCAT & $5504-5525$ & Reverse \\
P5-F & GATGGACAACTGCTTCCGAGG & $5503-5523$ & Forward \\
P5-R & ACACGCTAGTATGTGCTGGC & $6967-6986$ & Reverse \\
\hline
\end{tabular}

2 
Table 2 (on next page)

The information of 38 badnaviruses used in this study 
1 Table 2. The information of 38 badnaviruses used in this study.

\begin{tabular}{|c|c|c|c|}
\hline Virus & Abbreviation & Genbank no. & Host \\
\hline Aglaonema bacilliform virus & $\mathrm{ABV}$ & MH384837.1 & Aglaonema commutatum \\
\hline $\begin{array}{l}\text { Banana streak GF virus Yunnan } \\
\text { isolate }\end{array}$ & BSGFV-YN & MN296502 & Musa AAA group \\
\hline Banana streak $G F$ virus & BSGFV & $\mathrm{NC}_{-} 007002.1$ & Goldfinger (AAAB) \\
\hline Banana streak IM virus & BSIMV & NC_015507.1 & Musa sp. cv. Mshule \\
\hline Banana streak MY virus & BSMYV & KJ013509.1 & Musa acuminata cv. Cavendish \\
\hline Banana streak $O L$ virus & BSOLV & NC_003381.1 & Musa AAA group \\
\hline Banana streak UI virus & BSUIV & $\mathrm{NC}_{-} 015503.1$ & Musa sp. cv. Kisansa \\
\hline Banana streak UL virus & BSULV & NC_015504.1 & Musa sp. cv. Kibuzi \\
\hline Banana streak UM virus & BSUMV & $\mathrm{NC}_{-} 015505.1$ & Musa sp. cv. Mbwazirume \\
\hline Banana streak VN virus & BSVNV & KJ013510.1 & Musa acuminata cv. Cavendish \\
\hline Banana streak UA virus & BSUAV & NC_015502.1 & Musa sp. cv. Likhako \\
\hline $\begin{array}{l}\text { Banana streak virus Acuminata } \\
\text { Yunnan }\end{array}$ & BSV-Acum & NC_008018.1 & plaintain \\
\hline Birch leaf roll-associated virus & BLRaV & $\mathrm{NC}_{-} 040635.1$ & Betula pubescens \\
\hline Blackberry virus $F$ & $\mathrm{BbVF}$ & NC_029303.1 & Blackberry \\
\hline $\begin{array}{l}\text { Bougainvillea chlorotic vein banding } \\
\text { virus }\end{array}$ & BCVBV & NC_011592.1 & Chgainvillea spectabilis \\
\hline Cacao mild mosaic virus & CMMV & NC_033738.1 & Theobroma cacao \\
\hline Cacao bacilliform Sri Lanka virus & CBSLV & MF642736.1 & Theobroma cacao \\
\hline Cacao yellow vein banding virus & CYVBV & NC_033739.1 & Theobroma cacao \\
\hline Cacao swollen shoot virus & CSSV & NC_001574.1 & Theobroma cacao \\
\hline Commelina yellow mottle virus & ComYMV & NC_ 001343.1 & Commelina \\
\hline Canna yellow mottle associated virus & CaYMV & KY971493.1 & Canna sp. \\
\hline Citrus yellow mosaic virus & CYMV & EU708317.1 & Acid lime \\
\hline Dioscorea bacilliform virus & DBV & NC_ 009010.1 & Dioscorea sansibarensis \\
\hline Fig badnavirus 1 & FBV-1 & $\mathrm{NC}_{-} 017830.1$ & Fig \\
\hline Grapevine vein clearing virus & GVCV & NC_015784.2 & Grapevine (Chardonel) \\
\hline $\begin{array}{l}\text { Gooseberry vein banding associated } \\
\text { virus }\end{array}$ & GVBaV & NC_018105.1 & $\begin{array}{l}\text { Ribes rubrum cv. Holandsky } \\
\text { cerveny }\end{array}$ \\
\hline $\begin{array}{l}\text { Grapevine Roditis leaf discoloration- } \\
\text { associated virus }\end{array}$ & GRLDaV & NC_027131.1 & Vitis vinifera \\
\hline Jujube mosaic-associated virus & $\mathrm{JMaV}$ & NC_035472.1 & Ziziphus jujube \\
\hline Kalanchoe top-spotting virus & KTSV & NC_004540.1 & Kalanchoe blossfeldiana \\
\hline Pineapple bacilliform CO virus & $\mathrm{PBCOV}$ & NC_014648.1 & Pineapple plants \\
\hline Piper yellow mottle virus & PYMV & NC_022365.1 & Piper nigrum \\
\hline $\begin{array}{l}\text { Pagoda yellow mosaic associated } \\
\text { virus }\end{array}$ & PYMAV & NC_024301.1 & $\begin{array}{l}\text { Styphnolobium japonicum (L.) } \\
\text { Schott }\end{array}$ \\
\hline Rubus yellow net virus & RYNV & KM078034.1 & Rubus sp. \\
\hline
\end{tabular}




\begin{tabular}{llll} 
Sugarcane bacilliform MO virus & SBMOV & NC_008017.1 & Sugarcane \\
Sweet potato pakakuy virus & SPPV & NC_015655.1 & Sweet potato \\
Taro bacilliform virus & TaBV & NC_004450.1 & Taro \\
Wisteria badnavirus 1 & WBV-1 & NC_034252.1 & Wisteria sinensis \\
Yacon necrotic mottle virus & YNMV & NC_026472.1 & Yacon \\
\hline
\end{tabular}

2 


\section{Figure 1}

Overlapping PCR amplification and schematic genome organization of Banana streak GF virus YN isolate (BSGFV-YN)

Figure 1. Overlapping PCR amplification and schematic genome organization of Banana streak GF virus YN isolate (BSGFV-YN). (A), the complete genome of BSGFV-YN was amplified by using seven overlapping PCR of P1, ORF I, ORFII, P2, P3, P4 and P5. (B), the putative three open reading frames (ORFs) are indicated and the predicted domains of movement protein (MP), coat protein $(C P)$, aspartic protease $(A P)$, reverse transcriptase $(R T)$ and Ribonuclease $H$ (RNase H) within ORFIII are shown. Numbers above indicate the total number of nucleotide sequences of the ORFIII. The amino acid sequences of $1^{\text {st }}$ cysteine-rich and $2^{\text {nd }}$ cysteine-rich regions were also indicated.

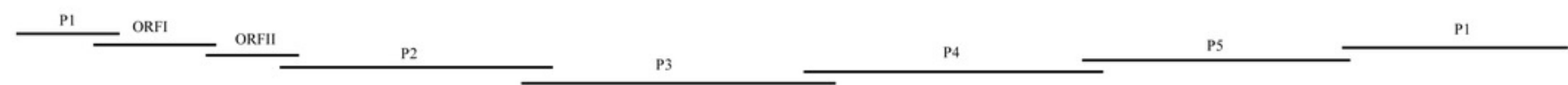

в

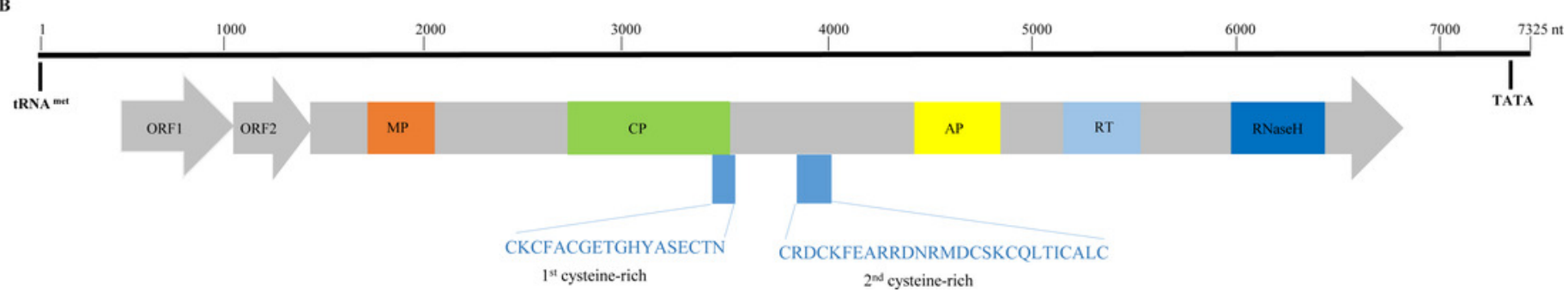




\section{Figure 2}

Comparison of amino acid sequences of the conserved domains in the putative ORFIII encoded polyprotein of BSGFV-YN with those of representative badnaviruses

Figure 2. Comparison of amino acid sequences of the conserved domains in the putative ORFIII encoded polyprotein of BSGFV-YN with those of representative badnaviruses. The predicted domains of movement protein (MP), coat protein (CP), aspartic protease (AP), reverse transcriptase (RT) and Ribonuclease H (RNase H) within ORFIll are shown. Two cysteine-rich regions are highlights with green color. 

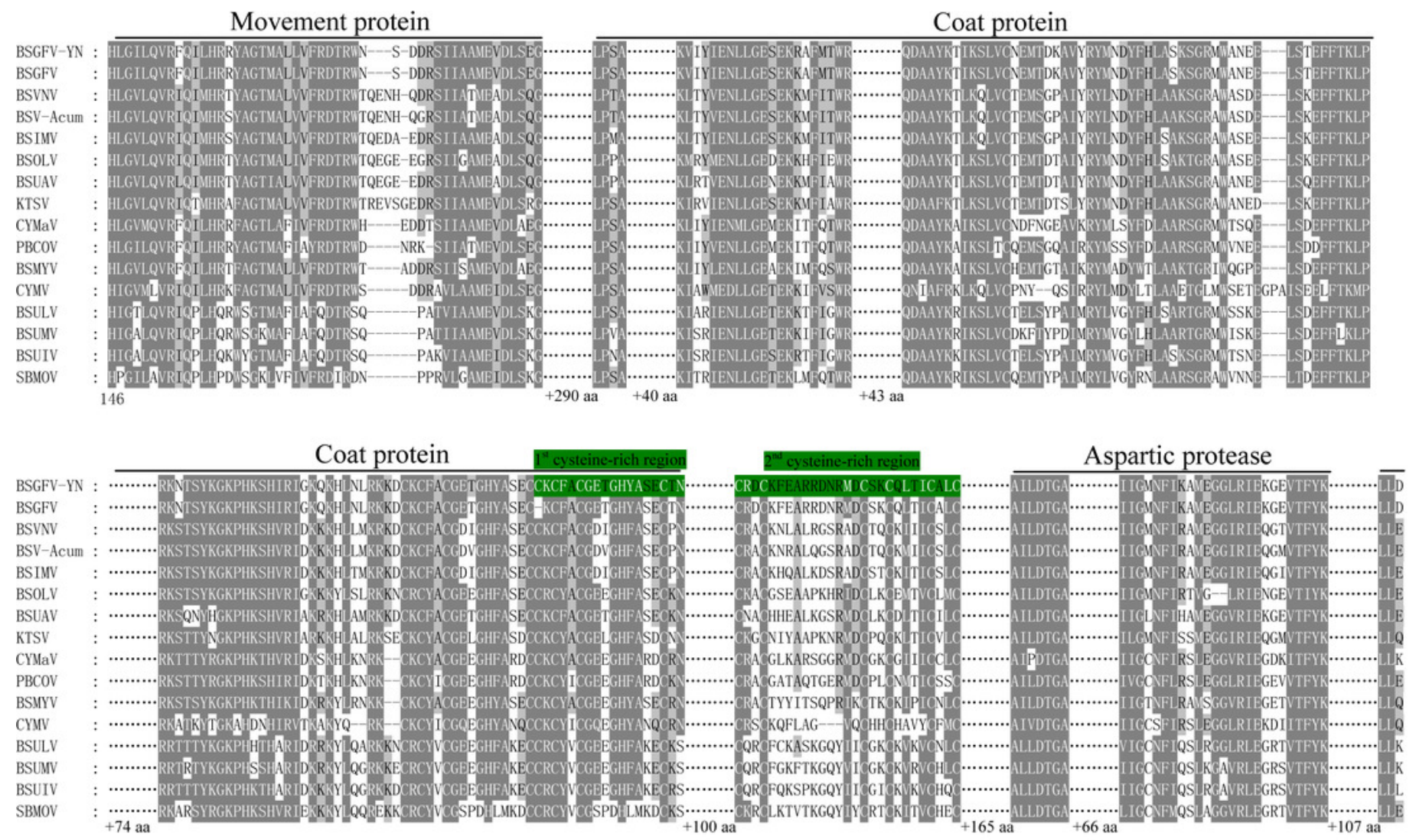

Reverse transcriptase

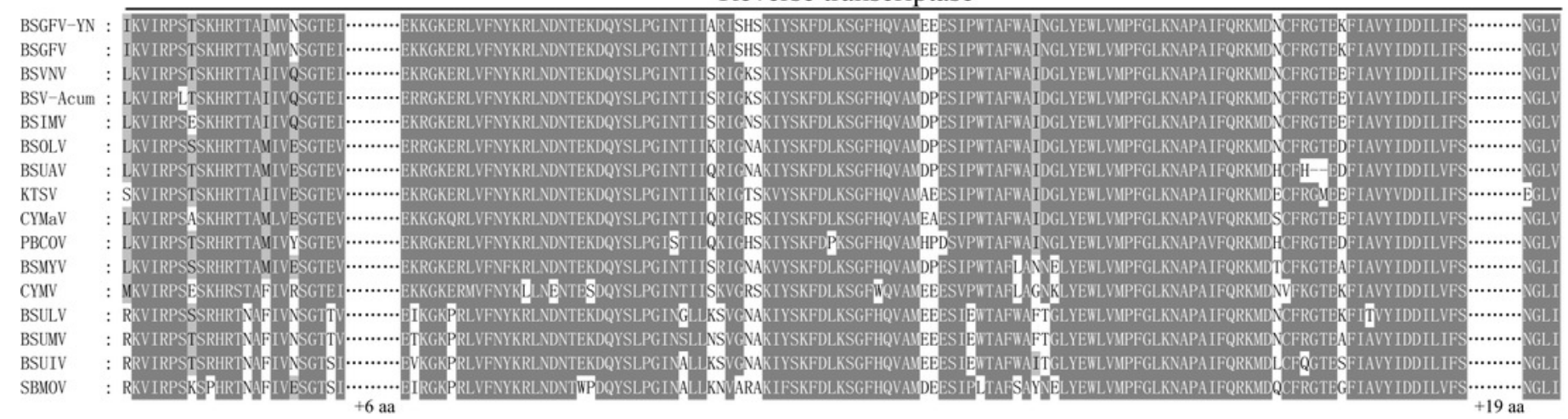

Ribonuclease $\mathrm{H}$

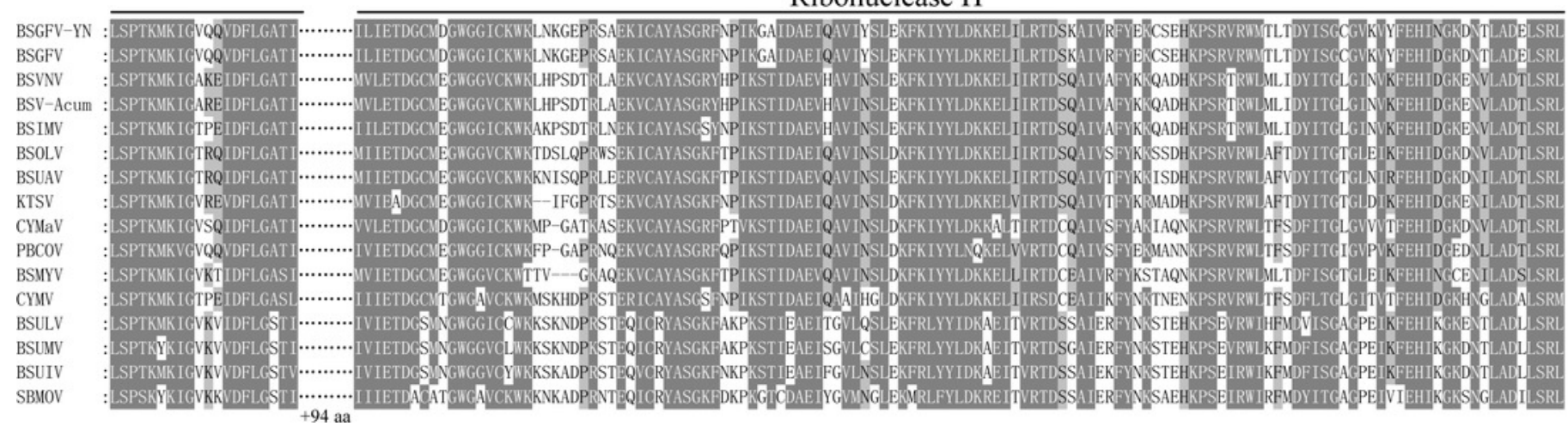




\section{Figure 3}

Comparison of non-coding region sequences of the BSGFV-YN with BSGFV Goldfinger.

Figure 3. Comparison of non-coding region sequences of the BSGFV-YN with BSGFV

Goldfinger. The repeat sequences were indicated in different color. Three "Repeat S"

sequences (red color) and two "Repeat L" sequences (blue color) are shown.

Repeat S Repeat L

BSGFV-YN : AGCACATACTGGCGTGTAAAGGCATCTGGTTGTCCCCAGAAGGCCTAAAGTTAGTGCGTTCCAACGCACATCTGCGTGTA : 7049

BSGFV : AGCACATACTAGCGTGTAAAGGCATCTGGTTGTCCCCAGAAGGCCTAAAGTTAGTGCGTTCCAAC---------------- : 7049

$$
\text { Repeat S Repeat L Reat S }
$$

BSGFV-YN : AAGGCATCTGGTTGTCCCCAGAAGGCCTAAAGTTAGTGCGTTCCAACGCACATCTGTGTGTAAAGGTATCTGGCTGTTTC : 7129

BSGFV : - ----------------------------------- GCACACCTATGTGTAAAGGTATCTGGCTGTTTC : 7129

BSGFV-YN : CAGACGCTACCTCCCTCTTT : 7149

BSGFV : CAGACGCTACCTCCCTCTTT : 7149 


\section{Figure 4}

Phylogenetic tree of the complete genome sequences of BSGFV-YN and other members of Badnavirus were conducted in MEGA6

Figure 4. Phylogenetic tree of the complete genome sequences of BSGFV-YN and other members of Badnavirus were conducted in MEGA6. The evolutionary history was inferred using the Neighbor-Joining method and its distances were computed using the $p$-distance method. The percentage of replicate trees in which the associated taxa clustered together in the bootstrap test (1000 replicates) is shown next to the branches. The analysis involved 38 complete genome sequences in Badnavirus. All positions containing gaps and missing data were eliminated. There were a total of 3805 positions in the final dataset. 


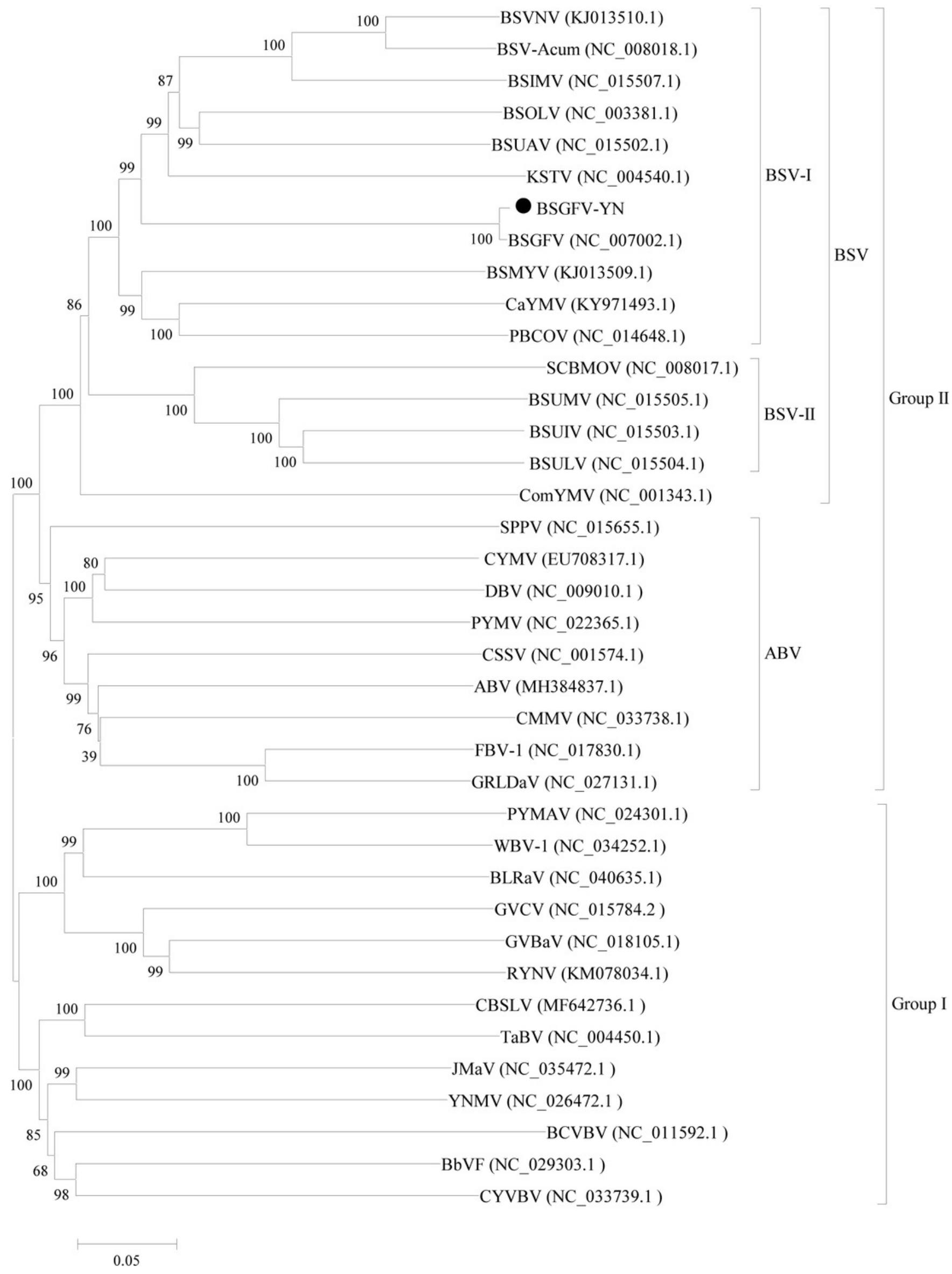

Peer) reviewing PDF | (2019:09:41325:2:0:CHECK 9 Dec 2019) 


\section{Figure 5}

Phylogenetic tree of the amino acid sequences of BSGFV ORFIII and other ORFIlls of the members in Badnavirus were conducted in MEGA6

Figure 5. Phylogenetic tree of the amino acid sequences of BSGFV ORFIII and other ORFIlls of the members in Badnavirus were conducted in MEGA6. The evolutionary history was inferred using the Neighbor-Joining method and the evolutionary distances were computed using the p-distance method. The percentage of replicate trees in which the associated taxa clustered together in the bootstrap test (1000 replicates) is shown next to the branches. The analysis involved 37 ORFIll amino acid sequences. All positions containing gaps and missing data were eliminated. There were a total of 1117 positions in the final dataset. 


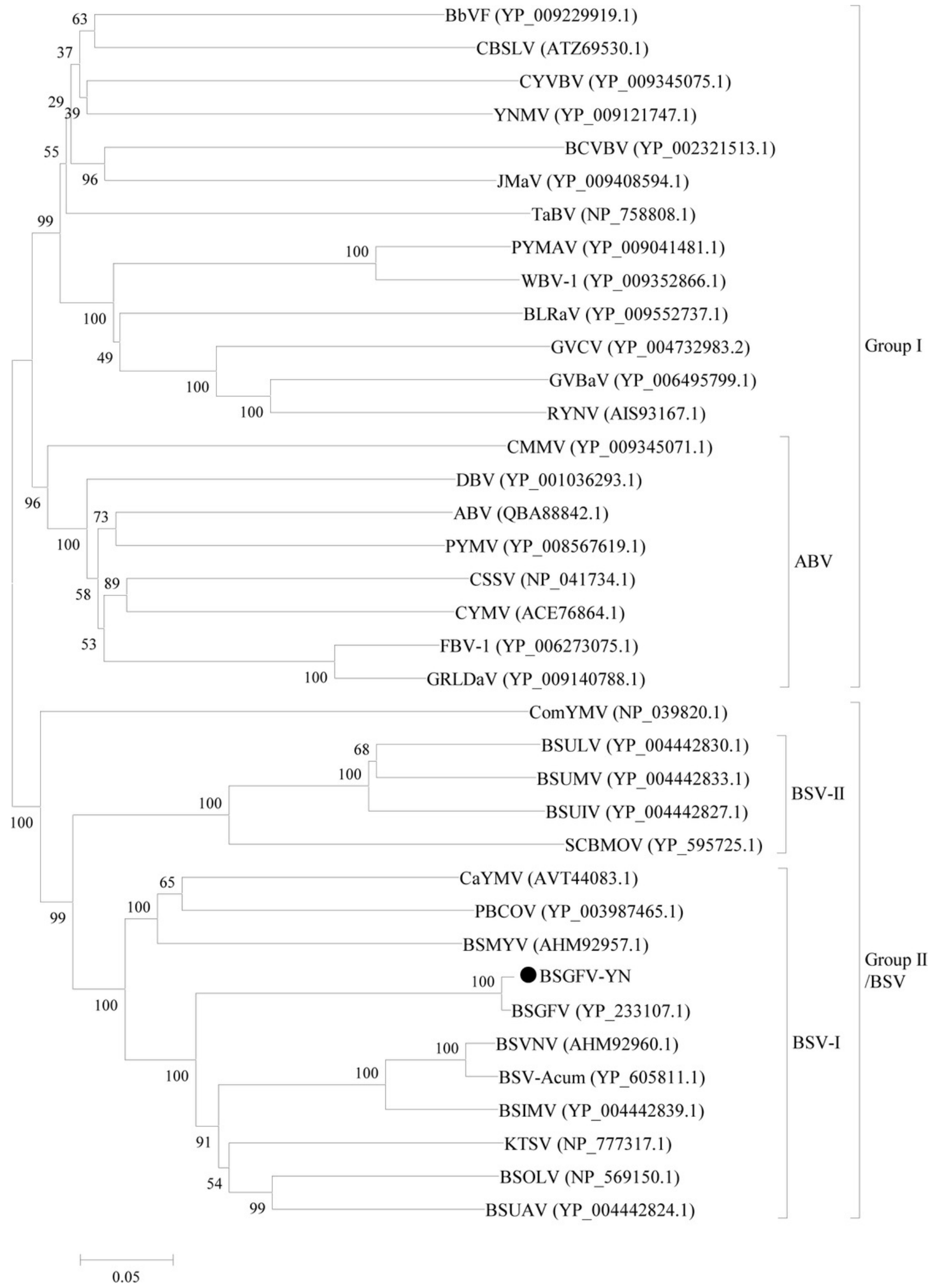

Peer) reviewing PDF | (2019:09:41325:2:0:CHECK 9 Dec 2019) 


\section{Figure 6}

Phylogenetic tree of the complete genome sequences of BSGFV-YN and other BSV isolates were conducted in MEGA6

Figure 6. Phylogenetic tree of the complete genome sequences of BSGFV-YN and other BSV isolates were conducted in MEGA6. The evolutionary history was inferred using the NeighborJoining method and the evolutionary distances were computed using the p-distance method. The percentage of replicate trees in which the associated taxa clustered together in the bootstrap test (1000 replicates) is shown next to the branches. The analysis involved 12 nucleotide sequences. All positions containing gaps and missing data were eliminated. There were a total of 6121 positions in the final dataset. Bold fonts are the host names of the viruses. 


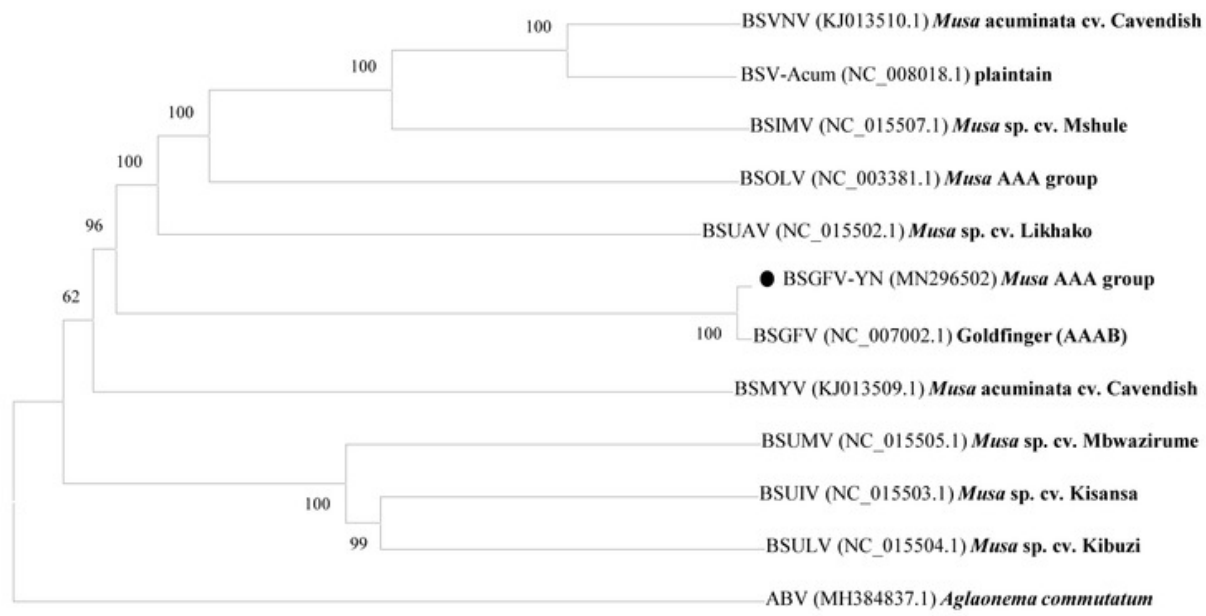

0.05 